\title{
ANALISIS PERBEDAAN TARIF RIIL DENGAN TARIF PAKET INA- CBG PADA PEMBAYARAN KLAIM JAMKESMAS PASIEN RAWAT INAP DI RSUD KABUPATEN SUKOHARJO
}

\author{
Agustin Ika Wijayanti ${ }^{1}$, Sri Sugiarsi ${ }^{2}$ \\ ${ }^{1}$ RSUD Sukoharjo, ${ }^{2}$ APIKES Mitra Husada Karanganyar \\ agustin_iw@yahoo.com ${ }^{1}$, sri_sugiarsi@yahoo.com ${ }^{2}$
}

\begin{abstract}
ABSTRAK
Within disparity use of real and Indonesia Case Based Groups (INA-CBG) fare, often triggering an assumption lead to prejudice of billing fact-manipulation which conducted by hospital management. The action is often causing financial deprivation over patient or the service payer (JAMKESMAS). Real fare is carry out by hospital based on fee for service proposal appointed by local government. INA-CBG is package of billing system based on service group category.

The aim of the research is analyzing the disparity of use between real and INA-CBG fare upon hospitalized care service toward JAMKESMAS claim-payment at Sukoharjo District General Hospital.

The research is analytic-observational type using retrospective design. Qualitative and quantitative data analysis is use, involving document study and in-depth interview as data gathering technique. Hypothesis verification acquired with the use of Wilcoxon test.

The result exhibit a significant different between real and INA-CBG fare with value of $p=0.001$. The disparity arise as the result of variety of health service tariff standard, length of stay, sofware utilization, accuracy of diagnose and service procedure coding, and deficiency of clinical pathway in Sukoharjo District General Hospital.
\end{abstract}

Key words: claim, Jamkesmas, real fare, INA-CBG

\section{PENDAHULUAN}

Sistem INA-CBG'S adalah aplikasi yang digunakan sebagai aplikasi pengajuan klaim Rumah Sakit, Puskesmas dan semua Penyedia Pelayanan Kesehatan (PPK) bagi masyarakat miskin Indonesia. Case Base Groups (CBG's), yaitu cara pembayaran perawatan pasien berdasarkan diagnosisdiagnosis atau kasus-kasus yang relatif sama. Rumah Sakit akan mendapatkan pembayaran berdasarkan rata-rata biaya yang dihabiskan oleh untuk suatu kelompok diagnosis.Rumah Sakit Umum Daerah (RSUD) Kabupaten Sukoharjo telah menjalankan program Indonesia Case Based Groups (INA-CBG) sejak tanggal 1 Oktober
2010 sebagai landasan perhitungan biaya klaim pasien Jaminan Kesehatan Masyarakat (Jamkesmas).

Menurut Pusat Pembiayaan dan Jaminan Kesehatan (2010), dalam situs resminya menyampaikan kecenderungan meningkatnya biaya pemeliharaan kesehatan menyulitkan akses masyarakat terhadap pelayanan kesehatan yang dibutuhkannya.Keadaan ini terjadi terutama pada keadaan dimana pembiayaannya harus ditanggung sendiri (out of pocket) dalam sistem pembayaran pelayanan kesehatan tunai (fee for service).Peningkatan biaya itu mengancam akses dan mutu pelayanan kesehatan dan karenanya harus dicari solusi 
untuk mengatasi masalah pembiayaan kesehatan ini. Solusi masalah pembiayaan kesehatan mengarah pada peningkatan pendanaan kesehatan agar mencukupi untuk mendukung pembangunan kesehatan sebagai investasi sumber daya manusia, dengan pendanaan pemerintah yang terarah untuk kegiatan kesehatan masyarakat seperti pemberantasan penyakit menular dan penyehatan lingkungan, promosi kesehatan serta biaya pemeliharaan kesehatan penduduk miskin. Sedangkan pendanaan masyarakat harus diefisienkan dengan pendanaan gotong-royong untuk berbagi risiko gangguan kesehatan, dalam bentuk jaminan kesehatan sebagaimana UndangUndang Nomor 40 tentang Sistem Jaminan Sosial Nasional di mana jaminan kesehatan merupakan program prioritas yang akan dikembangkan untuk mencapai kepesertaan semesta. Arah pencapaian kepesertaan semesta jaminan kesehatan pada akhir 2014 telah ditetapkan menurut Rencana Pembangunan Jangka Menengah (RPJM).

Menurut Thabrany dalam Hatta (2011), faktor-faktor yang dapat mempengaruhi biaya kesehatan antara lain:

1. Pada garis besarnya, biaya pelayanan medik di rumah sakit terus meningkat dari tahun ke tahun di negara manapun.Komponen inflasi biaya rumah sakit mencakup dua pertiga kenaikan biaya rumah sakit dan sepertiga kenaikan biaya bersumber dari pelayanan teknologi baru yang lebih baik dan lebih mahal. Inflasi biaya kesehatan selalu lebih tinggi dari biaya umum karena dalam banyak hal pimpinan rumah sakit tidak punya kendali atas biaya pelayanan medik di rumah sakit itu. Selain rumah sakit, kebijakan pemerintah, pembayar pihak ketiga seperti asuransi, tenaga kesehatan sendiri, dan masyarakat tidak memiliki insentif untuk mengendalikan biaya;

2. Tingginya tagihan rumah sakit, yang menjadi biaya bagi pihak asuransi, mendorong pihak asuransi atau pemerintah (dalam hal biaya rumah sakit bagi penduduk dibayar pemerintah, seperti yang dilakukan di Malaysia), untuk mengembangkan sistem pembayaran prospektif.

Berdasarkan pengamatan terhadap klaim pelayanan pasien peserta Jamkesmas 2010, besaran klaim menggunakan paket INA-CBG berbeda dengan biaya riil yang dikeluarkan pihak rumah sakit yang menggunakan standar perhitungan fee for service sesuai Peraturan Daerah setempat. Hal tersebut berlaku pada klaim pelayanan rawat jalan maupun rawat inap kelas tiga pada pasien peserta Jamkesmas. Perbedaan tersebut secara tidak langsung dapat mencerminkan pelayanan kesehatan yang diberikan rumah sakit kepada pasien berada di bawah standar yang telah ditetapkan oleh Pusat Pembiayaan dan Jaminan Kesehatan $\left(\mathrm{P}_{2} \mathrm{JK}\right)$ Kementrian Kesehatan Republik Indonesia selaku penyelenggara program Jamkesmas. Terdapat kesan bahwa rumah sakit diuntungkan dari perbedaan tarif riil dengan tarif paket INA-CBG itu, sehingga 
merugikan pihak penyelenggara Jamkesmas maupun pasien. Terdapat kendala dalam pelaksanaan Jamkesmas pada tahun 2010, salahsatunya yaitu dalam hal pembayaran (MenKes, 2011). Biaya pembayaran paket seringkali terdapat selisih antara tarif paket dan tarif riil yang sering kali dianggap tidak mencukupi. Hal ini terjadi akibat belum komprehensifnyapemahamanpenyelenggaraa $\mathrm{n}$ pola pembayaran dengan INA-DRGs terutama oleh dokter danpetugas lainnya yang menyebabkan belum terlaksananya pelayanan yang efisien

Pada survei pendahuluan diperoleh sampel data pada 10 pasien rawat inap peserta Jamkesmas bulan Oktober 2010 yang telah dihitung klaimnya menggunakan paket INA-CBG menunjukkan bahwa terdapat perbedaan tarif paket INA-CBG dengan biaya riil, serta terdapat perbedaan rata-rata lama dirawat (ALOS) standar paket dengan lama dirawat (LOS) riil. Penelitian ini relevan dengan penelitian Sugeng (2010), yang menyatakan bahwa ada perbedaan signifikan $(\mathrm{p}=0,001)$ antara biaya pelayanan kesehatan dengan sistem pembayaran INA-DRG dan non INA-DRG pada pasien diare infeksius di RSUP DR. Sardjito, Yogyakarta. Berdasar latar belakang tersebut perlu dilakukananalisis perbedaan tarif riil dengan tarif paket Indonesia Case Based Groups (INA-CBG) pada pembayaran klaim pasien rawat inap peserta Jamkesmas di RSUD Kabupaten Sukoharjo.

\section{METODE PENELITIAN}

Penelitian ini merupakan penelitian kuantitatif dan kualitatif dengan menggunakan metode observasi dan wawancara mendalam. Populasi obyek dalam penelitian ini adalah seluruh berkas klaim rawat inap pada pasien Jamkesmas bulan Oktober hingga Desember 2010 yang berjumlah 889 berkas dan sebagai populasi subyek adalah petugas verifikator. Besar sampel dalam penelitian ini sebanyak 276 berkas klaim Jamkesmas yang diambil teknik simple random sampling. Variabel bebas dalam penelitian ini adalah system pembayaran kesehatan yang meliputi sitem pembayaran fee for service dan INA CBG's. Sebagai variable terikat adalah tarif. Data penelitian akan dianalisis dengan menggunakan uji $\mathrm{t}$ sampel berpasangan (paired t-test) untuk data berdistribusi normal atau uji Wilcoxon untuk data berdistribusi tidak normal.

\section{HASIL}

\section{Karakteristik Pasien Jamkesmas}

Pasien jamkesmas yang berobat ke rumah sakit sebagian besar pulang dalam keadaan sembuhsejumlah 780 pasien sembuh $(87,74 \%), \quad 30$ pasien dirujuk $(3,37 \%), 25$ pasien pulang paksa $(2,81 \%), 54$ pasien meninggal $(6,07 \%)$, terlihat pada gambar 1.

Pasien rawat inap jamkesmas sebagian besar adalah perempun sejumlah 498 orang $(56,02 \%)$, sebagaimana terlihat pada gambar 2. 
Pasien Rawat Inap Jamkesmas menurut kelompok umur, terbanyak terbanyak yaitu kelompok umur 40-49 tahun sejumlah 150 pasien $(16,87 \%)$ dan kelompok umur 30-39 tahun sejumlah 148 pasien $(16,65 \%)$. Sedangkan kelompok umur dengan jumlah pasien yang paling sedikit adalah kelompok umur 90-100 tahun sejumlah 4 pasien $(0,45 \%)$. Hal ini terlihat pada Gambar 3.

Pasien Rawat Inap Jamkesmas menurut kasus atau jenis penyakit, kasus terbanyak yaitu kasus penyakit dalam sejumlah 382 pasien $(42,97 \%)$, kasus penyakit kebidanan dan kandungan (obsgyn) sejumlah 150 pasien $(16,87 \%)$, kasus penyakit bedah sejumlah 148 pasien (16,65\%). Sedangkan kasus yang paling sedikit adalah kasus penyakit kulit kelamin sejumlah 5 pasien $(0,56 \%)$, dan kasus penyakit jiwa sejumlah 1 pasien $(0,11 \%)$, sebagaimana terlihat pada Gambar 4.

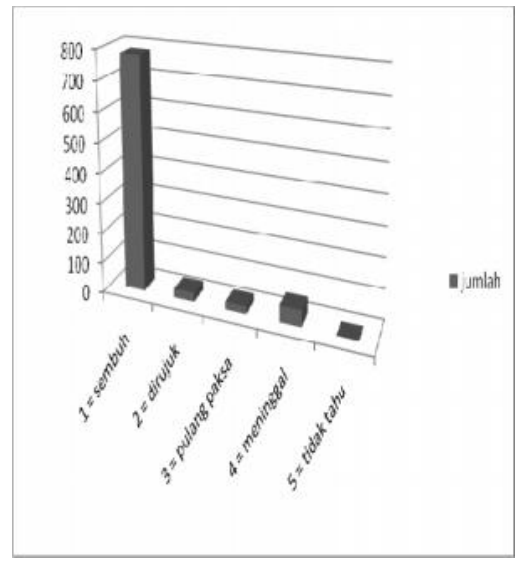

Gambar 1. Distribusi Pasien Jamkesmas Menurut Cara Keluar

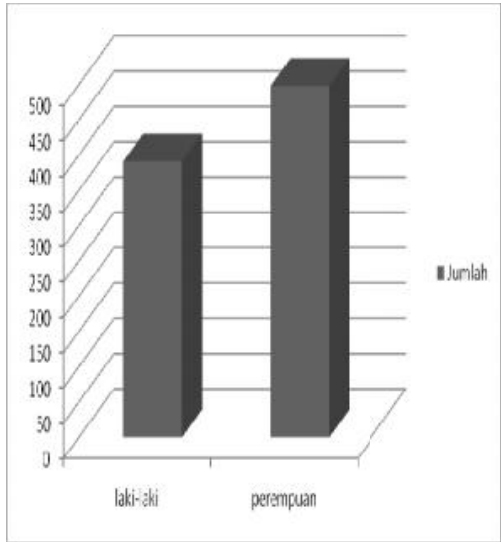

Gambar 2. Distribusi Pasien Jamkesmas Menurut Jenis Kelamin

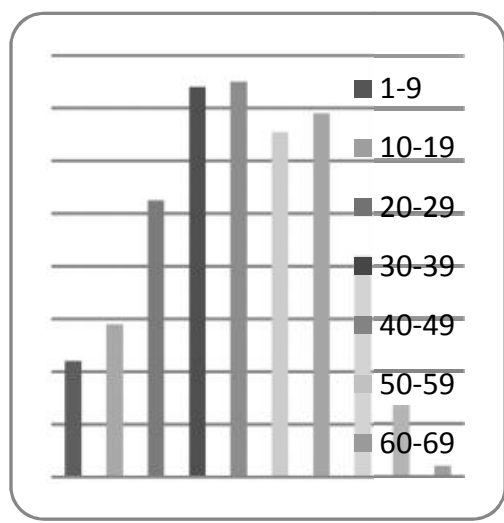

Gambar 3. Distribusi Pasien Jamkesmas Menurut Kelompok Umur

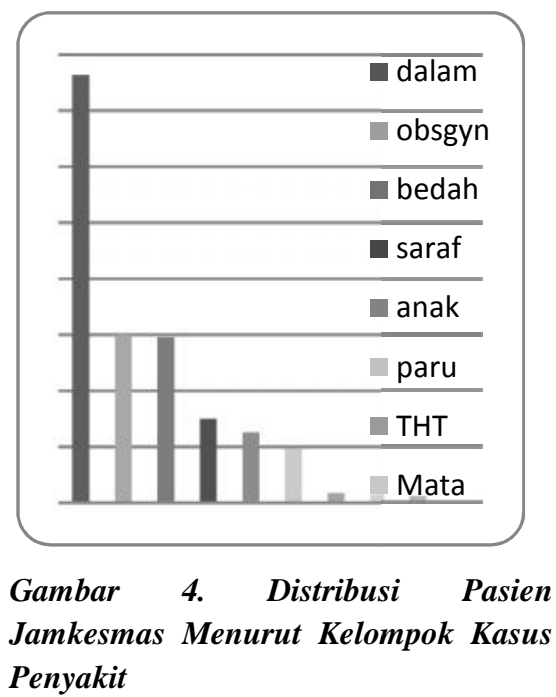




\section{UJI Hipotesis}

Tabel 1. Hasil Uji Statistik

\begin{tabular}{lll}
\hline Deskripsi & Tarif Riil & $\begin{array}{l}\text { Tarif Paket } \\
\text { INA-CBG }\end{array}$ \\
\hline $\mathrm{N}$ & 276 & 276 \\
Mean & $1.561 .258,1$ & $2.664 .496,7$ \\
Minimum & 191.775 & 794.933 \\
Maksimum & 22.500 .175 & 10.024 .361 \\
Standar & $1.759 .288,36$ & $1.527 .333,68$ \\
Deviasi & & \\
\hline Wilcoxon & $=10,81$ & \\
$\mathrm{P}$ & $<0,001$ & \\
\hline
\end{tabular}

Tabel 1 menunjukkan bahwa dari 276 data pada tarif riil dan tarif paket INA-CBG, terdapat perbedaan rata-rata (mean) tarif riil (Rp 1.561.258,1) dengan mean tarif paket INA-CBG (Rp 2.664.496,7). Selain itu, juga terlihat perbedaan pada minimum tarif riil (Rp 191.775,00) dan maksimum tarif riil ( $R p$ 22.500.175,00) dengan minimum tarif paket INA-CBG (Rp 794.933,00) dan maksimum tarif paket INA-CBG (Rp 10.024.361,00). Sedangkan pada standar deviasi tarif riil dan tarif paket INA-CBG juga terdapat perbedaan, yaitu sebesar Rp 1.759.288,36 pada tarif riil dan $\mathrm{Rp} 1.527 .333,68$ pada tarif paket INA-CBG. Tabel tersebut juga menunjukkan perbedaan yang secara statistik signifikan pada tarif riil dan tarif paket INA-CBG ( $\mathrm{p}<0,001)$, serta nilai uji Wilcoxon $=10,81$.

Faktor penyebab Perbedaan Tarif Riil dengan Tarif Paket INA-CBG

Hasil wawancara dengan petugas Verifikator adalah sebagai berikut :

Tarif riil dihitung per rincian jenis pelayanan, dalam hal ini standar tarifnya sudah ditentukan dalam Peraturan Daerah. Sedangkan tarif INA-CBG dihitung berdasarkan akumulasi atau penggabungan kode diagnosis dan kode prosedur/tindakan ke dalam sebuah kode CBG yang standar tarifnya telah ditetapkan oleh Pemerintah Pusat

Lama Dirawat (Length of Stay) juga turut mempengaruhi perbedaan tarif riil dengan tarif paket INA-CBG. Hal tersebut dikarenakan Lama Dirawat pada tarif riil dihitung per hari, sehingga semakin lama pasien dirawat semakin besar pula biayanya. Sedangkan pada INA-CBG Lama Dirawat sudah ditentukan standarnya, sehingga meski pasien dirawat lama ataupun sebentar tarifnya akan tetap sesuai kode diagnosis dan kode prosedurnya

Penghitungan tarif pada INA-CBG menggunakan alat bantu berupa software yang telah ditentukan oleh Kementerian Kesehatan, sehingga keluaran tarifnya sudah pasti sesuai database yang telah ditetapkan. Namun pada penghitungan tarif riil di RSUD Kabupaten Sukoharjo belum menggunakan alat bantu software secara efektif, sehingga dimungkinkan untuk terjadi human error ketika mengentri tarif riil.

Ketepatan pengodean diagnosis dan prosedur akan mempengaruhi ketepatan tarif pada INA-CBG, dengan demikian jarak perbedaan tarif riil dengan tarif INA-CBG juga akan ditentukan oleh ketepatan pengodean.

RSUD Kabupaten Sukoharjo belum memiliki clinical pathway, sehingga pemberian pelayanan kesehatan pada pasien dengan kasus yang sama dapat berbeda-beda pada tiap dokter yang menanganinya. Misalnya pada acuan lama pasien dirawat, 
pemberian obat-obatan, pemberian tindakan medis maupun pemeriksaan penunjang

\section{PEMBAHASAN}

Berdasarkan analisis statistik diperoleh informasi bahwa terdapat perbedaan yang secara statistik signifikan antara tarif riil dan tarif paket INA-CBG pada pembayaran klaim Jamkesmas pasien rawat inap di RSUD Kabupaten Sukoharjo ( $\mathrm{p}=0,001)$. Selain itu juga terdapat perbedaan rata-rata (mean) tarif riil $(\operatorname{Rp} 1.561 .258,1)$ dengan mean tarif paket INA-CBG (Rp 2.664.496,7). Hasil penelitian hampir serupa juga disampaikan oleh Sugeng (2010), yang menyatakan bahwa ada perbedaan yang secara statistik signifikan pada biaya pelayanan kesehatan pasien Diare Infeksius dengan sistem pembayaran INA DRG dan non INA DRG di RSUP Dr. Sardjito Yogyakarta $(\mathrm{p}=0,001)$. Hasil penelitian Sugeng memiliki persamaan dengan yang dihasilkan oleh peneliti, yaitu sama-sama menemukan perbedaan antara pemberlakuan tarif riil dan tarif paket.

Perbedaan tersebut dapat dipengaruhi oleh beberapa faktor. Menurut Thabrani (2011), faktor-faktor yang mempengaruhi biaya kesehatan yaitu komponen inflasi biaya rumah sakit, kebijakan pemerintah, pembayar pihak ketiga (asuransi), maupun tenaga kesehatan sendiri. Sedangkan menurut Cleverly (1997), ada empat cara utama secara teknis agar biaya untuk sistem pembayaran paket (Cased Base Groups) dapat dikurangi, yaitu:
1. Mengurangi harga yang dibayar untuk sumber daya/input;

2. Mengurangi lama dirawat pasien;

3. Mengurangi intensitas pelayanan yang disediakan;

4. Meningkatkan efisiensi produksi.

Demikian halnya perbedaan tarif riil dengan tarif paket INA-CBG pada pembayaran klaim Jamkesmas pasien rawat inap di RSUD Kabupaten Sukoharjo yang di antaranya dilatarbelakangi oleh perbedaan standar tarif yang diterapkan, lama dirawat, keberadaan software, ketepatan pengodean diagnosis/prosedur, serta ketiadaan clinical pathway. Hal-hal yang melatarbelakangi perbedaan tarif riil dengan tarif paket tersebut secara garis besar sejalan dengan yang telah disampaikan oleh Cleverly dengan penjelasan sebagai berikut:

\section{Perbedaan standar tarif riil dengan tarif INA-CBG}

Pada perbedaan tarif riil dengan tarif paket INA-CBG di RSUD Kabupaten Sukoharjo, tarif riilnya dihitung per rincian jenis pelayanan, dalam hal ini standar tarifnya sudah ditentukan dalam Peraturan Daerah. Sedangkan tarif INA-CBG dihitung berdasarkan akumulasi atau penggabungan kode diagnosa dan kode prosedur/tindakan ke dalam sebuah kode CBG yang standar tarifnya telah ditetapkan oleh Pemerintah Pusat (Centre for Casemix Kemenkes RI). Perbedaan tarif terlihat begitu jelas karena pada dasarnya standar tarif dalam Peraturan Daerah Kabupaten Sukoharjo jauh lebih rendah dibanding standar tarif paket INACBG yang ditetapkan oleh Pemerintah 
Pusat. Hal tersebut terjadi karena penentuan standar tarif riil (Perda) disesuaikan dengan kemampuan ekonomi masyarakat di Kabupaten Sukoharjo.

Perbedaan standar tarif ini akhirnya turut mempengaruhi nominal tarif pelayanan kesehatan di RSUD Kabupaten Sukoharjo yang rata-ratanya jauh lebih rendah dibanding nominal klaim Jamkesmas menggunakan tarif paket INA-CBG. Oleh karena itu, peluang RSUD Kabupaten Sukoharjo untuk memperoleh keuntungan (surplus) dari selisih tarif riil dengan tarif paket INA-CBG juga semakin besar. Perolehan keuntungan tersebut dilaporkan kepada Pemerintah Daerah Kabupaten Sukoharjo karena rumah sakit berstatus milik Pemerintah Daerah.

\section{Perbedaan Lama Dirawat}

Lama Dirawat (Length of Stay) juga turut mempengaruhi perbedaan tarif riil dengan tarif paket INA-CBG. Hal tersebut dikarenakan Lama Dirawat pada tarif riil dihitung per hari, sehingga semakin lama pasien dirawat semakin besar pula biayanya. Sedangkan pada INA-CBG Lama Dirawat sudah ditentukan standarnya, sehingga meski pasien dirawat lama ataupun sebentar tarifnya akan tetap sesuai kode diagnosis dan kode prosedurnya.

Menurut Cleverly (1997), salah satu cara agar biaya untuk sistem pembayaran paket (Cased Base Groups) dapat dikurangi yaitu dengan mengurangi lama dirawat pasien. Sementara itu menurut Sudra (2009), dari aspek medis semakin panjang Lama Dirawat maka dapat menunjukkan kualitas kinerja medis yang kurang baik karena pasien harus dirawat lebih lama (lama sembuhnya). Sebaliknya, bila Lama Dirawat semakin pendek dapat diambil pengertian bahwa kualitas kinerja medis baik. Namun di sisi lain, pendeknya Lama Dirawat juga dipengaruhi oleh cara keluar pasien yang menurut Pusat Pembiayaan dan Jaminan Kesehatan (2010) terbagi ke dalam lima kategori, yaitu sembuh, rujuk, meninggal, pulang paksa, dan lain-lain.

Pada aspek ekonomis, semakin panjang Lama Dirawat berarti semakin tinggi biaya yang nantinya harus dibayar oleh pasien (pihak pembayar) dan diterima oleh rumah sakit. Hal tersebut hanya berlaku pada tarif riil saja, sedangkan pada tarif paket INACBG panjang atau pendeknya Lama Dirawat tidak berpengaruh terhadap besarnya biaya. Berdasarkan pengertian tersebut, jika RSUD Kabupaten Sukoharjo mampu mengatur pemberian pelayananan (dalam hal ini Lama Dirawat) secara efektif dan efisien maka memperbesar peluang terjadinya selisih (surplus) antara tarif riil dengan tarif paket INA-CBG.

\section{Keberadaan software}

Penghitungan tarif pada INA-CBG menggunakan alat bantu berupa software yang telah ditentukan oleh Kementrian Kesehatan, sehingga keluaran tarifnya sudah pasti sesuai database yang telah ditetapkan berdasarkan pengelompokan per kasus (gabungan dari kode diagnosis dan kode prosedur). Sedangkan pada penghitungan tarif riil di RSUD Kabupaten Sukoharjo belum menggunakan alat bantu software 
secara efektif, sehingga dapat terjadi human error ketika mengentri tarif riil karena membutuhkan ketelitian tinggi untuk menghitung tarif riil yang terperinci pada setiap pelayanan kepada pasien (tarif kamar, dokter, pemeriksaan penunjang, laboratorium, obat, alat medis habis pakai).

\section{Ketepatan pengodean diagnosis}

Ketepatan pengodean diagnosis dan prosedur akan mempengaruhi ketepatan tarif pada software INA-CBG, dengan demikian jarak perbedaan tarif riil dengan tarif INACBG juga akan ditentukan oleh ketepatan pengodean. Ketika pengodean tepat serta penentuan diagnosis primer dan sekunder juga tepat, maka tarif paket INA-CBG yang muncul juga tepat sesuai dengan derajat keparahan (severity level) dari kode diagnosis dan prosedur. Namun ketika pengodean tidak tepat, kemudian mengakibatkan derajat keparahan yang tidak tepat, maka tarif paket INA-CBG yang muncul pun tidak tepat pula. Hal itulah yang disebut dengan upcoding (menaikkan kode pada derajat keparahan yang lebih tinggi) yang semakin memperbesar selisih antara tarif riil dengan tarif paket INA-CBG. Sedangkan ketepatan pengodean diagnosis sendiri sangat dipengaruhi oleh ketepatan dan kelengkapan penulisan diagnosis oleh dokter pada berkas klaim Jamkesmas. Sebagai langkah pengendalian/pengawasan terhadap ketepatan pengodean, Pusat Pembiayaan dan Jaminan Kesehatan Kementrian Kesehatan RI telah membekali Verifikator Independen Jamkesmas dengan software, namun tetap dibutuhkan pengetahuan terhadap pengodean agar upcoding dapat diantisipasi.

\section{Ketiadaan clinical pathway}

RSUD Kabupaten Sukoharjo belum memiliki clinical pathway, sehingga pemberian pelayanan kesehatan pada pasien dengan kasus yang sama dapat berbeda-beda pada tiap dokter yang menanganinya. Misalnya pada acuan lama pasien dirawat, pemberian obat-obatan, pemberian tindakan medis maupun pemeriksaan penunjang. Hal tersebut juga mengakibatkan pemberian pelayanan kepada pasien kurang terkendali, bisa berlebihan atau justru pelayanan yang diberikan tidak relevan dengan penyakit yang diderita pasien karena ketiadaan standar pemberian pelayanan kesehatan.

Menurut pernyataan yang tertuang dalam Pedoman Pelaksanaan Jamkesmas Pusat Pembiayaan dan Jaminan Kesehatan Kementrian Kesehatan RI (2010), bahwa biaya jasa medis/jasa pelayanan ditetapkan Direktur RS setinggi-tingginya $44 \%$ atas biaya pelayanan kesehatan yang dilakukan. Jasa medis/jasa pelayanan tersebut meliputi biaya untuk pemberi pelayanan dalam rangka observasi, diagnosis, pengobatan, tindakan medis, perawatan, konsultasi, visite, dan/atau pelayanan medis lainnya, serta untuk pelaksana administrasi pelayanan.

Berdasarkan pernyataan tersebut, ketiadaan clinical pathway memiliki pengaruh besar terhadap selisih antara tarif riil dengan tarif paket INA-CBG. Sebagaimana yang telah disampaikan oleh Cleverly (1997), cara agar biaya untuk 
sistem pembayaran paket (Cased Base

Groups) dapat dikurangi, yaitu dengan mengurangi harga yang dibayar untuk sumber daya/input, mengurangi lama dirawat pasien, mengurangi intensitas pelayanan yang disediakan, serta meningkatkan efisiensi produksi/pelayanan.

Pada pernyataan dalam Pedoman Pelaksanaan Jamkesmas (2010), bahwa jasa medis/jasa pelayanan ditetapkan Direktur RS setinggi-tingginya $44 \%$ atas biaya pelayanan kesehatan yang dilakukan secara tidak langsung dapat memotivasi Pemberi Pelayanan Kesehatan (PPK) untuk memperoleh jasa medis/jasa pelayanan sebanyak mungkin, terlebih lagi dengan ketiadaan clinical pathway sebagai sarana pengendali dan standar pemberian pelayanan kesehatan. Hal ini sepintas dapat merugikan pihak pasien dari segi kualitas pelayanan kesehatan yang diterima, maupun pihak penyelenggara program Jamkesmas dalam hal pertanggungjawaban luncuran dana yang telah diberikan kepada rumah sakit. Jadi keberadaan clinical pathway merupakan suatu kebutuhan mendasar agar tenaga medis (terutama dokter) memiliki landasan dan dapat mempertanggungjawabkan pelayanan kesehatan yang diberikan kepada pasien.

\section{SIMPULAN}

1. Terdapat perbedaan yang secara statistik signifikan antara tarif riil dan tarif paket INA-CBG pada pembayaran klaim Jamkesmas pasien rawat inap di
RSUD Kabupaten Sukoharjo ( $\mathrm{p}=$ $0,001)$

2. Terdapat perbedaan yang secara statistik signifikan antara tarif riil dan tarif paket INA-CBG pada pembayaran klaim Jamkesmas pasien rawat inap pelayanan Penyakit Dalam $(\mathrm{p}=0,001)$ serta pelayanan Bedah $(\mathrm{p}=0,001) \mathrm{di}$ RSUD Kabupaten Sukoharjo

3. Tidak terdapat perbedaan yang secara statistik signifikan pada pembayaran klaim Jamkesmas pasien rawat inap pelayanan Obsgyn $(\mathrm{p}=0,191) \mathrm{di}$ RSUD Kabupaten Sukoharjo

4. Faktor-faktor yang menimbulkan perbedaan tarif riil dengan tarif klaim Jamkesmas paket INA-CBG pada pelayanan pasien rawat inap di RSUD Kabupaten Sukoharjo, antara lain:

a. Perbedaan standar tarif riil dengan tarif INA-CBG;

b. Perbedaan Lama Dirawat (Length of Stay);

c. Keberadaan software;

d. Ketepatan pengodean diagnosis;

e. RSUD Kabupaten Sukoharjo belum memiliki clinical pathway.

\section{DAFTAR PUSTAKA}

Budiarto, Eko. 2002. Biostatistika untuk Kedokteran dan Kesehatan Masyarakat. Jakarta: Penerbit Buku Kedokteran EGC.

Cleverly, William. 1997. Essentials of Health Care Finance, Fourth Edition. Maryland: Aspen Publishers Inc. 
Horton, Loretta. 2007. Calculating and Reporting Healthcare Statistics. USA: AHIMA.

Hazelwood, Anita dan Venable, Carol. 2007. Reimbursement Methodologies, dalam Johns, Merida .L, editor. Health Information Technology an Applied Approach Chapter 7. USA: AHIMA.

Hazelwood, Anita dan Venable, Carol. 2006. Reimbursement Methodologies, dalam Latour, Kathleen .M, dan Eichenwald-Maki, Shirley, editor. Health Information Management Concepts, Principles, and Practice Chapter 14. USA: AHIMA.

Jamaluddin, Bakhuri. 2010. Kapita Selekta Jaminan Kesehatan Masyarakat 2010. Banten: CV Media Medika.

Murti, Bhisma. 2010. Desain dan Ukuran Sampel untuk Penelitian Kuantitatif dan Kualitatif di Bidang Kesehatan. Yogyakarta: Gadjah Mada University Press.

Notoatmodjo, Soekidjo. 2002. Metodologi Penelitian Kesehatan. Jakarta: Rineka Cipta.

Nugrahani, Farida. 2002. Metodologi Penelitian Kualitatif, Teori dan Aplikasi. Surakarta: UNS Press.

Pusat Pembiayaan dan Jaminan Kesehatan. 2008. Jaminan Kesehatan Masyarakat. Diunduh 30 Agustus 2010.

http://www.ppjk.depkes.go.id.

Pusat Pembiayaan dan Jaminan Kesehatan. 2010. Pedoman Pelaksanaan
Jaminan Kesehatan Masyarakat 2010. Jakarta: Kementrian Kesehatan RI.

Pusat Pembiayaan dan Jaminan Kesehatan. 2011. Kurikulum dan Modul Pelatihan Tenaga Pelaksana Verifikasi Jamkesmas 2011. Jakarta: Kementrian Kesehatan RI.

Riwidikdo, Handoko. 2008. Statistik Kesehatan. Yogyakarta: Mitra Cendikia Press.

Sabarguna, Boy .S. 2006. Sistem Bantu Keputusan untuk Quality Management. Yogyakarta: Konsorsium RS Islam Jateng-DIY.

Sudra, Rano Indradi. 2009. Statistik Rumah Sakit dari Sensus Pasien dan Grafik Barber-Johnson hingga Statistik Kematian dan Otopsi. Yogyakarta: Graha Ilmu.

Sugeng. 2010. Analisis Lama Rawat dan Biaya Pelayanan Kesehatan pada Sistem Pembayaran INA DRG dan Non INA DRG di RSUP Dr. Sardjito Yogyakarta. [Skripsi]. Surakarta: Fakultas Ilmu Kesehatan UMS.

Sugiyono. 2010. Metode Penelitian Kuantitatif, Kualitatif, dan $R \& D$. Bandung: CV Alfabeta.

Thabrani, Hasbullah. 2011. Sistem Pembayaran Fasilitas Kesehatan. Dalam Hatta (ed.). Pedoman Manajemen Informasi Kesehatan di Sarana Pelayanan Kesehatan. Jakarta: UI-Press. 